\title{
Combined Heat and Mass Transfer Steady Flow of Viscous Fluid over a Vertical Plate with Large Suction
}

\author{
S. M. Arifuzzaman, Md. Manjiul Islam, Md. Mohidul Haque
}

Mathematics Discipline, Khulna University, Khulna, Bangladesh

\section{Email address:}

arifsm42@gmail.com (S. M. Arifuzzaman), manjiul.math@gmail.com (Md. M. Islam), mmhaque@math.ku.ac.bd (Md. M. Haque)

\section{To cite this article:}

S. M. Arifuzzaman, Md. Manjiul Islam, Md. Mohidul Haque. Combined Heat and Mass Transfer Steady Flow of Viscous Fluid over a Vertical Plate with Large Suction. International Journal of Science, Technology and Society. Vol. 3, No. 5, 2015, pp.236-242.

doi: $10.11648 /$ j.ijsts.20150305.13

\begin{abstract}
Combined heat and mass transfer of a viscous fluid along a semi-infinite vertical plate with large suction is studied analytically. Perturbation technique is used as main tool for the analytical approach. Viscous fluid behavior of heat and mass transfer over a vertical plate with large suction has been considered and its similarity equations have been obtained. Similarity equations of the corresponding momentum, temperature and concentration equations are derived by employing the usual similarity technique. The dimensionless similarity equations for momentum, temperature and concentration equation solved analytically by perturbation technique. The obtained numerical values of fluid velocity, temperature and concentration are drawn in figures. The results are discussed in detailed with the help of graphs to observe the effects of various parameters on the flow variables. Lastly, the important findings are concluded here.
\end{abstract}

Keywords: Mass Transfer, Heat Transfer, Eckert Number, Schmidt Number, Large Suction

\section{Introduction}

The heat transfer flows play a decisive role in many engineering applications as distillation, condensation, evaporation, rectification and absorption of a fluid as well as in fluids condensing or boiling at a solid surface. The heat transfer processes are of great interest in power engineering, metallurgy, astrophysics and geophysics. A natural convective heat transfer flow of fluid was first studied by Finston (1956) [1]. Sparrow and Gregg (1958) computed a similar solution for laminar free convection from a non-isothermal vertical plate [2]. A Finite difference solution of transient free convective flow over an isothermal plate was obtained by Soundalgekar and Ganesan (1981) [3]. A numerical study on the natural convective cooling problem of a vertical plate was completed by Camargo et al. (1996) [4].

The processes of mass transfer are of great interest in the production of materials in order to obtain the desired properties of a substance. Separation processes in chemical engineering such as the drying of solid materials, distillation, extraction and absorption are all affected by the process of mass transfer. Chemical reactions including combustion processes are often decisively determined by the mass transfer. Callahan and Marner (1976) studied a free convective unsteady flow with mass transfer past a semi-infinite plate [5]. An investigation on free convective unsteady flow with mass transfer past an infinite vertical porous plate with constant suction was completed by Soundalgekar and Wavre (1977) [6]. Transient free convection flow on a semi-infinite vertical plate with mass transfer was observed by Soundalgekar and Ganesan (1980) [7].

The combined heat and mass transfer flows play a special role in power engineering, metallurgy, condensation, evaporation and rectification of a fluid. In the separation processes as drying of solid materials, distillation, extraction and absorption; the combined heat and mass transfer occur due to buoyancy forces caused by temperature difference and concentration difference. Pera and Gebhart (1971) was the first author to study the natural convective heat and mass transfer problem [8]. Singh et al. (2003 investigated the combined heat and mass transfer hydromagnetic flow of a viscous incompressible fluid along an infinite vertical porous plate [9]. Chamkha and Khaled (2001) investigated the problem of coupled heat and mass transfer from an inclined plate in the presence of absorption [10]. Hence the main aim of this research project was to study a combined heat and mass transfer steady flow of a viscous fluid along a semi-infinite vertical plate with large suction. 


\section{Mathematical Model of Flow}

A heat and mass transfer steady flow of a viscous fluid along a semi-infinite vertical plate was considered. The flow was assumed to be in the $x$-direction, which was chosen along the plate in upward direction and $y$ - axis was normal to it. Initially, it was considered that the plate as well as the fluid particle was at rest at the same temperature $T\left(=T_{\infty}\right)$ and the same species concentration level $C\left(=C_{\infty}\right)$ at all points, where $C_{\infty}$ and $T_{\infty}$ are fluid concentration and temperature species of uniform flow respectively. It was also assumed that the fluid particles outside the boundary layer moved with a uniform velocity $U_{0}$. The suitable physical configuration with co-ordinate systems are shown in Fig 2.1.

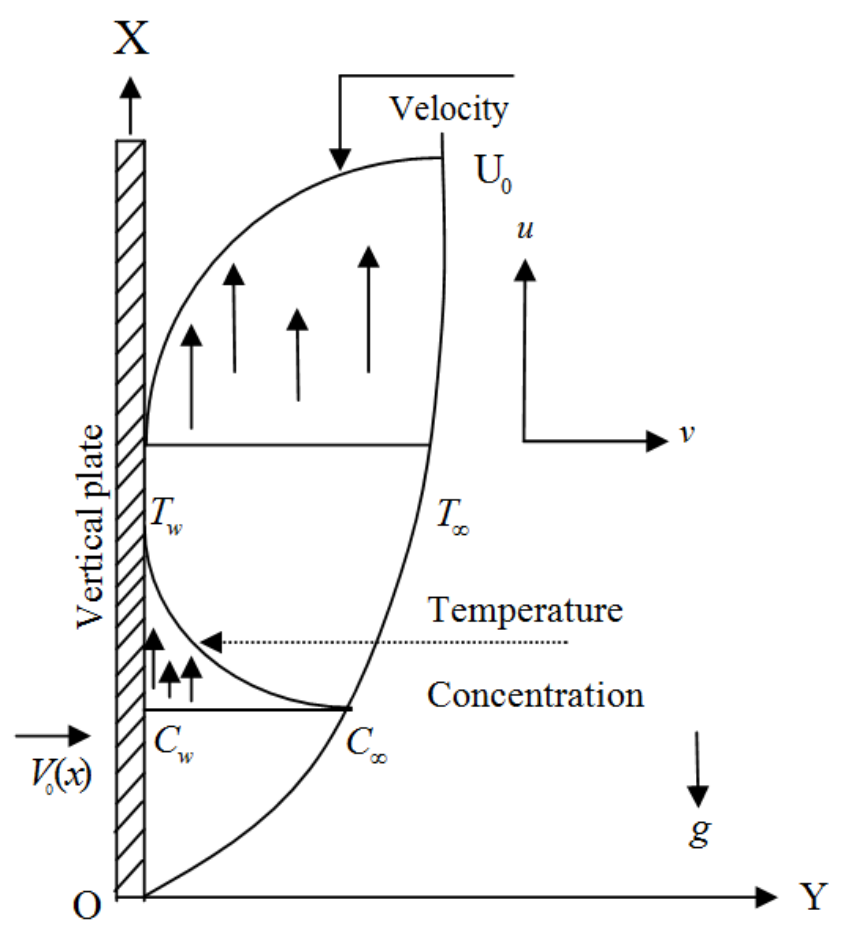

Fig. 2.1. Physical Configuration of Flow.

The following is the system of coupled governing non-linear partial differential equations.

The continuity equation

$$
\frac{\partial u}{\partial x}+\frac{\partial v}{\partial y}=0
$$

The momentum equation

$$
\begin{aligned}
& u \frac{\partial u}{\partial x}+v \frac{\partial u}{\partial y}=g \beta\left(T-T_{\infty}\right) \\
& +g \beta^{*}\left(C-C_{\infty}\right)+v\left(\frac{\partial^{2} u}{\partial y^{2}}\right)
\end{aligned}
$$

The Energy Equation

$$
\begin{aligned}
& u \frac{\partial T}{\partial x}+v \frac{\partial T}{\partial y}=\frac{k}{\rho c_{p}} \frac{\partial^{2} T}{\partial y^{2}} \\
& +\frac{v}{\rho c_{p}}\left(\frac{\partial u}{\partial y}\right)^{2}
\end{aligned}
$$

The Concentration Equation

$$
u \frac{\partial C}{\partial x}+v \frac{\partial C}{\partial y}=D_{m}\left(\frac{\partial^{2} C}{\partial y^{2}}\right)
$$

and the boundary conditions are,

$$
\begin{aligned}
& u=0, v=V_{0}(x), T=T_{w} \quad C=C_{w} \text { at } \mathrm{y}=0 \\
& u=U_{0}, v=0, \quad T \rightarrow T_{\infty} \quad C \rightarrow C_{\infty} \text { at } \mathrm{y} \rightarrow \infty
\end{aligned}
$$

where, $x, y$ be the Cartesian coordinate; $u, v$ are velocity components, $g$ is the local acceleration due to gravity, $\beta$ is the is the thermal expansion coefficient, $\beta^{*}$ is the is the concentric expansion coefficient, $T_{w}$ denotes the wall temperature, $C_{w}$ is the species concentration at the wall, $v$ is the kinematic viscosity, $\rho$ is density, $k$ is thermal conductivity, $C_{p}$ is specific heat at constant pressure, $D_{m}$ is coefficient of mass diffusivity, $m$ is mass per unit area.

\section{Mathematical Formulation}

Since the researchers goal was to attain similarly solutions of the problem the researchers introduced the following variables,

$$
\begin{aligned}
& \eta=y \sqrt{\frac{U_{0}}{2 v x}} \\
& \psi=\sqrt{2 v U_{0} x} f(\eta) \\
& u=\frac{\partial \psi}{\partial y} \text { and } \quad v=-\frac{\partial \psi}{\partial x}
\end{aligned}
$$

Where,

$$
\begin{gathered}
u=U_{0} f^{\prime}(\eta) \\
u \frac{\partial u}{\partial x}=-\frac{U_{0}^{2}}{2 x} \eta f^{\prime}(\eta) f^{\prime \prime}(\eta) \\
\frac{\partial^{2} u}{\partial y^{2}}=\frac{U_{0}^{2}}{2 v x} f^{\prime \prime \prime}(\eta) \\
\therefore v=\sqrt{\frac{v U_{0}}{2 x}}\left[\eta f^{\prime}(\eta)-f(\eta)\right]
\end{gathered}
$$

Above values we get these;

$$
f^{\prime \prime \prime}+f f^{\prime \prime}+G_{r} \theta+G_{m} \varnothing=0
$$




$$
\begin{aligned}
& \theta^{\prime \prime}+P_{r} f \theta^{\prime}+P_{r} E_{c} f^{\prime \prime 2}=0 \\
& \varnothing^{\prime \prime}+\mathrm{S}_{\mathrm{C}} f(\eta) \varnothing^{\prime}(\eta)=0
\end{aligned}
$$

where, $\mathrm{G}_{\mathrm{r}}=\frac{2 x}{U_{0}{ }^{2}} \mathrm{~g} \beta\left(T_{w}-T_{\infty}\right)$ is the Grashof Number and $\mathrm{G}_{\mathrm{m}}=\frac{2 x}{U_{0}^{2}} \mathrm{~g} \beta\left(C_{w}-C_{\infty}\right)$ is the Modified Grashof Number. $\mathrm{P}_{\mathrm{r}}=\frac{\mu c_{p}}{k}=\frac{\rho v c_{p}}{k}$ is the Prandtl Number and $\mathrm{E}_{\mathrm{C}}=\frac{U_{0}^{2}}{c_{p}\left(T_{w}-T_{\infty}\right)}$ is the Eckert Number.

With the boundary conditions

$$
\begin{aligned}
& f=f_{\mathrm{w}}, f^{\prime}=0, \theta=1, \varnothing=1 \quad \text { at } \quad \eta=0 \\
& f^{\prime}=1, \quad \theta=0, \varnothing=0 \quad \text { at } \quad \eta \rightarrow \infty
\end{aligned}
$$

Where, $f_{\mathrm{w}}=-V(x) \sqrt{\frac{2 x}{U_{0} v}}$ the transpiration parameter and prime is denotes derivatives with respect to $\eta$. Here $f_{\mathrm{w}}>0$ indicates the suction and $f_{\mathrm{w}}<0$ the injection.

\section{Mathematical Analysis}

$$
\begin{aligned}
& \xi=\eta f_{\mathrm{w}}, \\
& f(\eta)=f_{\mathrm{w}} \mathrm{F}(\xi), \\
& \theta(\eta)=f_{\mathrm{w}}^{2} \mathrm{H}(\xi) \\
& \varnothing(\eta)=f_{\mathrm{w}}^{2} G(\xi)
\end{aligned}
$$

By using the conversion in the equation (10) and (11) we have,

$$
\begin{aligned}
& f_{\mathrm{w}}^{4} \mathrm{~F}^{\prime \prime \prime}+f_{\mathrm{w}} \mathrm{F} f_{\mathrm{w}}^{3} \mathrm{~F}^{\prime \prime}+\mathrm{G}_{\mathrm{r}} f_{\mathrm{w}}^{2} \mathrm{H} \\
& +\mathrm{G}_{\mathrm{m}} f_{\mathrm{w}}^{2} \mathrm{G}=0 \\
& f_{\mathrm{w}}^{4} \mathrm{H}^{\prime \prime}+\mathrm{P}_{\mathrm{r}} f_{\mathrm{w}} \mathrm{F} \cdot f_{\mathrm{w}}^{3} \mathrm{H}^{\prime} \\
& +\mathrm{P}_{\mathrm{r}} \mathrm{E}_{\mathrm{C}} f_{\mathrm{w}}^{6} \mathrm{~F}^{\prime \prime 2}=0 \\
& f_{\mathrm{w}}^{4} \mathrm{G}^{\prime \prime}+\mathrm{S}_{\mathrm{C}} f_{\mathrm{w}} \mathrm{F} f_{\mathrm{w}}^{3} G^{\prime}=0
\end{aligned}
$$

Therefore the equation (13) with boundary conditions as given below

$$
\begin{aligned}
& \left.\begin{array}{l}
\mathrm{F}^{\prime \prime \prime}+\mathrm{FF}^{\prime \prime}+\varepsilon \mathrm{G}_{\mathrm{r}} \mathrm{H}+\varepsilon \mathrm{G}_{\mathrm{m}} \mathrm{G}=0 \\
\mathrm{H}^{\prime \prime}+\mathrm{P}_{\mathrm{r}} \mathrm{F} \mathrm{H}^{\prime}+\mathrm{P}_{\mathrm{r}} \mathrm{E}_{\mathrm{C}} \frac{1}{\varepsilon} \mathrm{F}^{\prime \prime 2}=0 \\
\mathrm{G}^{\prime \prime}+\mathrm{S}_{\mathrm{C}} \mathrm{FG} \mathrm{G}^{\prime}=0
\end{array}\right\} \\
& \mathrm{F}=1, \mathrm{~F}^{\prime}=0, \mathrm{H}=\varepsilon, \mathrm{G}=0 \text { at } \xi=0 \\
& \mathrm{~F}^{\prime}=\varepsilon, \quad \mathrm{H}=0, \mathrm{G}=0 \quad \text { at } \quad \xi \rightarrow \infty
\end{aligned}
$$

where, $\varepsilon=\frac{1}{f_{\mathrm{w}}^{2}}$

Now for the large solution $f_{\mathrm{w}}>1$.If $f_{\mathrm{w}}$ is very large then $\varepsilon$ will be very small. Therefore following Bestman (1990) and Singh \& Dikshit (1988), F, H and G can be expended in terms of the small perturbation quantity $\varepsilon$ as,

$$
\begin{gathered}
\mathrm{F}(\xi)=1+\varepsilon \mathrm{F}_{1}(\xi)+\varepsilon^{2} \mathrm{~F}_{2}(\xi)+ \\
\mathrm{H}(\xi)=\varepsilon \mathrm{H}_{1}(\xi)+\varepsilon^{2} \mathrm{H}_{2}(\xi)+ \\
\mathrm{G}(\xi)=\varepsilon \mathrm{G}_{1}(\xi)+\varepsilon^{2} \mathrm{G}_{2}(\xi)+
\end{gathered}
$$

Taking the order $\mathrm{O}(\varepsilon)$ the system (17) becomes,

$$
\left.\begin{array}{l}
\mathrm{F}_{1}^{\prime \prime \prime}+\mathrm{F}_{1}^{\prime \prime}=0 \\
\mathrm{H}_{1}^{\prime \prime}+\mathrm{P}_{\mathrm{r}} \mathrm{H}_{1}^{\prime}+\mathrm{P}_{\mathrm{r}} \mathrm{E}_{\mathrm{C}} \mathrm{F}_{1}^{\prime \prime 2}=0 \\
\mathrm{G}_{1}^{\prime \prime}+\mathrm{S}_{\mathrm{C}} \mathrm{G}_{1}^{\prime}=0
\end{array}\right\}
$$

With boundary condition

$$
\left.\begin{array}{ll}
\mathrm{F}_{1}=0, \mathrm{~F}_{1}^{\prime}=0, \mathrm{H}_{1}=1, \mathrm{G}_{1}=1 & \text { at } \begin{array}{c}
\xi=0 \\
\mathrm{~F}_{1}^{\prime}=1, \mathrm{H}_{1}=0, \mathrm{G}_{1}=0
\end{array} \text { at } \xi \rightarrow \infty
\end{array}\right\}
$$

Again for order $\mathrm{O}\left(\varepsilon^{2}\right)$ the system (17) becomes,

$$
\left.\begin{array}{l}
\mathrm{F}_{2}^{\prime \prime \prime}+\mathrm{F}_{2}^{\prime \prime}+\mathrm{F}_{1} \mathrm{~F}_{1}^{\prime \prime}+\mathrm{G}_{\mathrm{r}} \mathrm{H}_{1}+\mathrm{G}_{\mathrm{m}} \mathrm{G}_{1}=0 \\
\mathrm{H}_{2}^{\prime \prime}+\mathrm{P}_{\mathrm{r}}\left(\mathrm{F}_{1} \mathrm{H}_{1}^{\prime}+\mathrm{H}_{2}^{\prime}+2 \mathrm{E}_{\mathrm{C}} \mathrm{F}_{1}^{\prime \prime} \mathrm{F}_{2}^{\prime \prime}\right)=0 \\
\mathrm{G}_{2}{ }^{\prime \prime}+\mathrm{S}_{\mathrm{C}}\left(\mathrm{F}_{1} \mathrm{G}_{1}^{\prime}+\mathrm{G}_{2}{ }^{\prime}\right)=0
\end{array}\right\}
$$

with boundary condition

$$
\left.\begin{array}{ll}
\mathrm{F}_{2}=0, \mathrm{~F}_{2}^{\prime}=0, \mathrm{H}_{2}=0, \mathrm{G}_{2}=0 & \text { at } \quad \xi=0 \\
\mathrm{~F}_{2}^{\prime}=0, \mathrm{H}_{2}=0, \mathrm{G}_{2}=0 & \text { at } \xi \rightarrow \infty
\end{array}\right\}
$$

\section{Solution}

The first order solution becomes;

$$
\begin{aligned}
& \mathrm{F}_{1}=-1+\xi+\mathrm{e}^{-\xi}, \mathrm{H}_{1}=\mathrm{e}^{-\mathrm{P}_{\mathrm{r}} \xi}+\mathrm{A}_{11} \mathrm{e}^{-2 \xi} \\
& \text { and } \mathrm{G}_{1}=\mathrm{e}^{-\mathrm{S}_{\mathrm{C}} \xi}
\end{aligned}
$$


and the second order solution becomes

$$
\begin{aligned}
& \mathrm{F}_{2}=-3 \xi \mathrm{e}^{-\xi}-\xi \mathrm{e}^{-\xi}-\frac{1}{2} \xi^{2} \mathrm{e}^{-\xi} \\
& +\mathrm{A}_{21} \mathrm{e}^{-\mathrm{P}_{\mathrm{r}} \xi}+\mathrm{A}_{22} \mathrm{e}^{-2 \xi}+\mathrm{A}_{23} \mathrm{e}^{-\mathrm{S}_{\mathrm{C}} \xi} \\
& \mathrm{H}_{2}=\mathrm{A}_{27} \mathrm{e}^{-\mathrm{S}_{\mathrm{C}} \xi}+\mathrm{A}_{28} \mathrm{e}^{-3 \xi}+\left(\mathrm{B}_{12}+\mathrm{B}_{13} \xi+\mathrm{B}_{14} \xi^{2}\right) \mathrm{e}^{-2 \xi} \\
& +\left(\mathrm{A}_{30} \xi-\mathrm{B}_{11} \xi^{2}\right) \mathrm{e}^{-\mathrm{P}_{\mathrm{r}} \xi}+\mathrm{A}_{31} \mathrm{e}^{-\xi\left(\mathrm{P}_{\mathrm{r}}+1\right)} \\
& \mathrm{G}_{2}=\left(\mathrm{C}_{11}+\mathrm{C}_{12} \xi+\mathrm{C}_{13} \xi^{2}\right) \mathrm{e}^{-\mathrm{S}_{\mathrm{C}} \xi}+\mathrm{C}_{11} \mathrm{e}^{-\xi}
\end{aligned}
$$

\section{Results and Discussions}

The analytical solutions were obtained by using the perturbation technique. In order to analyze the physical situation of the model, the researchers computed the numerical values of the flow variables for different values of suction parameter $\left(f_{w}\right)$, Grashof number $\left(\mathrm{G}_{r}\right)$, Modified Grashof Number $\left(G_{m}\right)$, Schmidt number $\left(S_{C}\right)$, Eckert Number $\left(E_{c}\right)$ and the Prandtl Number $\left(P_{r}\right)$. The fluid velocity, temperature and concentration versus the non-dimensional coordinate variable $\eta$ are displayed in Figs. 6.1 - 6.15. It is noted in Fig. 6.1 that the velocity remains unchanged with the increasing of Eckert Number $\left(\mathrm{E}_{\mathrm{c}}\right)$. Fig.6.2 represents the velocity increase with the increase of the value of the suction parameter $\left(f_{w}\right)$. From Fig. 6.3 it can be seen that the velocity decreases with the increase of the value of the Grashof number $\left(\mathrm{G}_{r}\right)$.Fig. 6.4 shows that the velocity remains unchanged with the increase of the value of the Prandtl Number $\left(P_{r}\right)$. In Fig. 6.5, the velocity decreases with the increase of the value of the Schmidt number $\left(\mathrm{S}_{\mathrm{C}}\right)$. In Fig. 6.6, the fluid temperature decreases with the increase of the value of the Eckert Number $\left(E_{c}\right)$. Fig. 6.7 shows that the temperature decreases with the increase of the value of the suction parameter $\left(f_{w}\right)$. It is found in Fig. 6.8 that the temperature remains unchanged with the increase of the value of the Grashof number $\left(G_{r}\right)$. Fig. 6.9 shows that the temperature decreases with the increase of the value of the Prandtl Number $\left(\mathrm{P}_{\mathrm{r}}\right)$. Fig. 6.10 shows that the temperature increases with the increase of the value of the Schmidt number $\left(\mathrm{S}_{\mathrm{C}}\right)$.Fig. 6.11 shows that the concentration remains unchanged with the increase of the value of the Eckert Number $\left(E_{c}\right)$. It is shown in Fig. 6.12 that the concentration decreases with the increase of the value of the suction parameter $\left(f_{w}\right)$.Fig. 6.13 shows that the concentration remains unchanged with the increase of the value of the Grashof number $\left(\mathrm{G}_{r}\right)$. It is observed from Fig. 6.14 that the concentration remains unchanged with the increase of the value of the Prandtl Number $\left(P_{r}\right)$. Fig. 6.15 shows that the concentration decreases with the increase of the value of the
Schmidt number $\left(\mathrm{S}_{\mathrm{C}}\right)$.

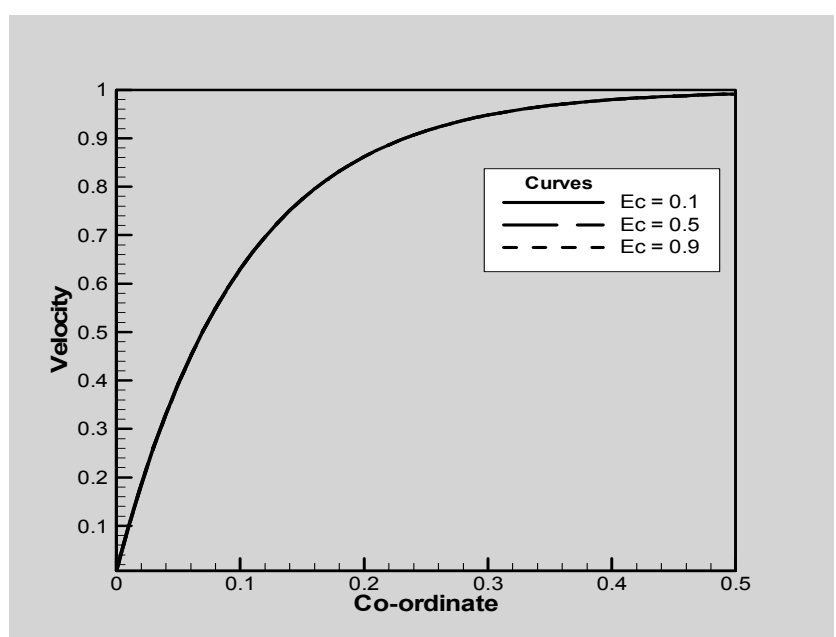

Fig. 6.1. Velocity profiles for different values of $\mathrm{E}_{\mathrm{C}}$ with $\mathrm{G}_{\mathrm{m}}=0.2$, $\mathrm{G}_{\mathrm{r}}=0.2, \quad \mathrm{P}_{\mathrm{r}}=0.5, \quad f_{\mathrm{w}}=10.0$ and $\mathrm{S}_{\mathrm{C}}=0.3$.

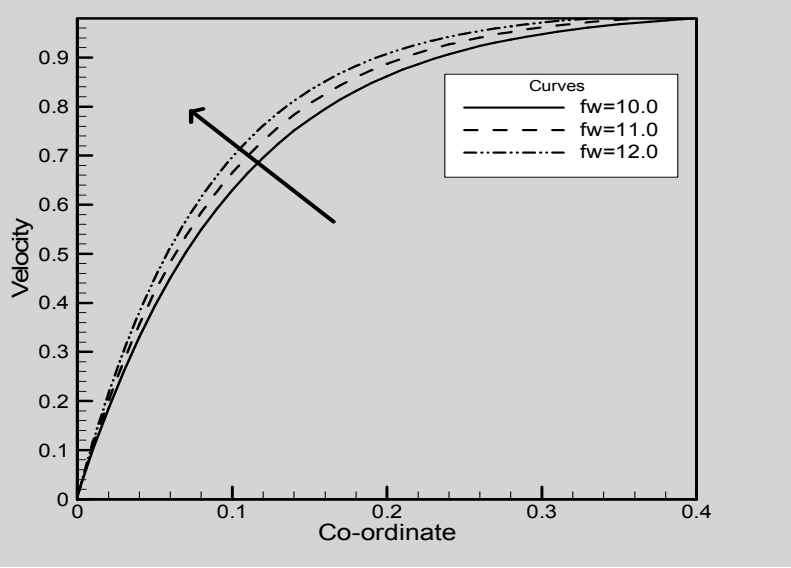

Fig. 6.2. Velocity profiles for different values of $f_{\mathrm{w}}$ with $\mathrm{G}_{\mathrm{m}}=0.2$, $\mathrm{G}_{\mathrm{r}}=0.2, \quad \mathrm{P}_{\mathrm{r}}=0.5, \quad \mathrm{E}_{\mathrm{C}}=0.1$ and $\mathrm{S}_{\mathrm{C}}=0.3$.

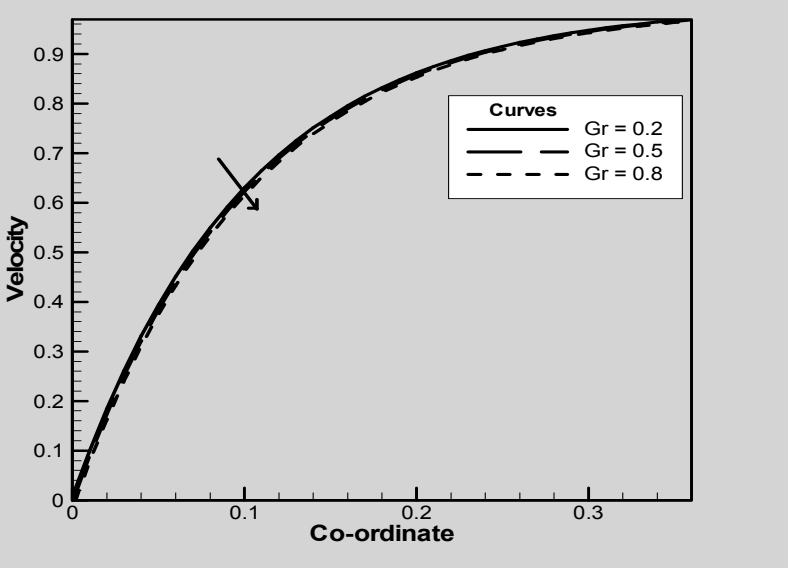

Fig. 6.3. Velocity profiles for different values of $\mathrm{G}_{\mathrm{r}}$ with $\mathrm{G}_{\mathrm{m}}=0.2$, $\mathrm{E}_{\mathrm{C}}=0.1, \quad \mathrm{P}_{\mathrm{r}}=0.5, \quad f_{\mathrm{w}}=10.0$ and $\mathrm{S}_{\mathrm{C}}=0.3$. 


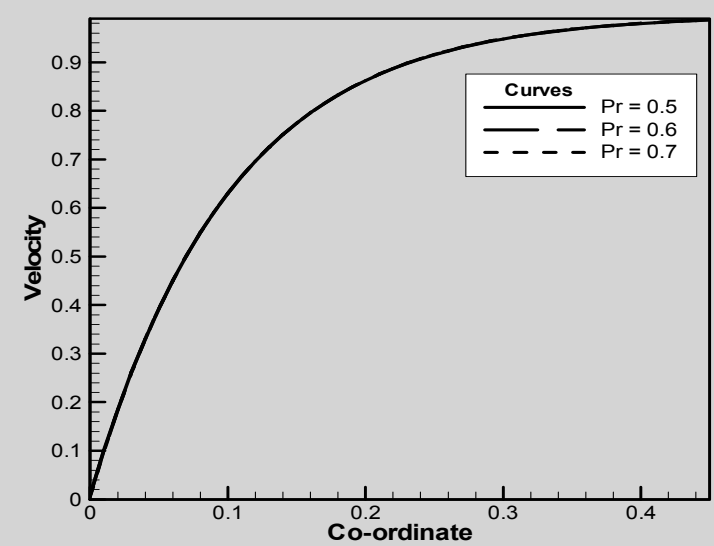

Fig. 6.4. Velocity profiles for different values of $\mathrm{P}_{\mathrm{r}}$ with $\mathrm{G}_{\mathrm{m}}=0.2$, $\mathrm{E}_{\mathrm{C}}=0.1, \quad \mathrm{G}_{\mathrm{r}}=0.2, \quad f_{\mathrm{w}}=10.0$ and $\mathrm{S}_{\mathrm{C}}=0.3$.

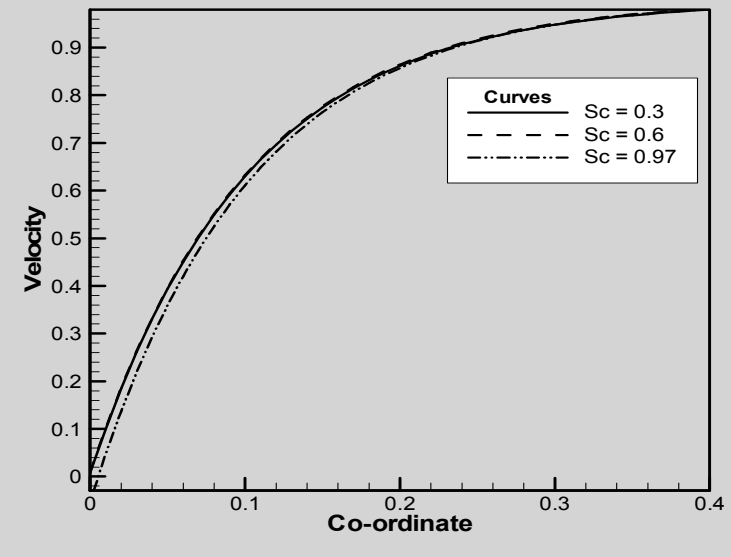

Fig. 6.5. Velocity profiles for different values of $\mathrm{S}_{\mathrm{C}}$ with $\mathrm{G}_{\mathrm{m}}=0.2$, $\mathrm{E}_{\mathrm{C}}=0.1, \quad \mathrm{G}_{\mathrm{r}}=0.2, \quad f_{\mathrm{w}}=10.0$ and $\mathrm{P}_{\mathrm{r}}=0.5$.

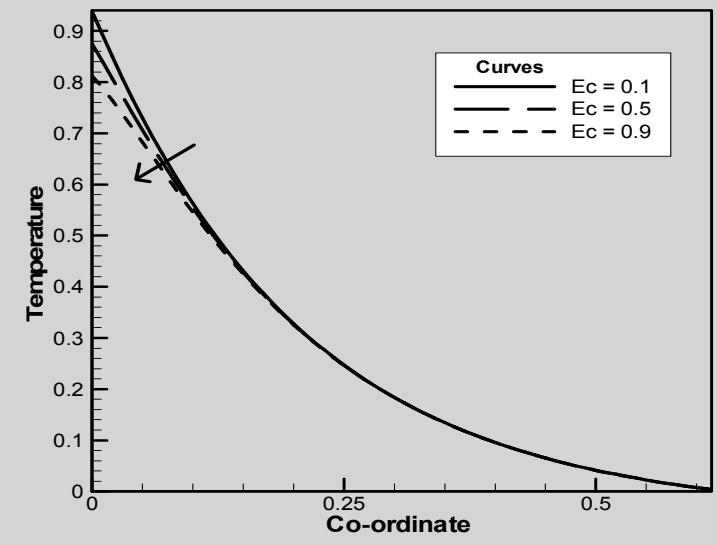

Fig. 6.6. Temperature profiles for different values of $\mathrm{E}_{\mathrm{C}}$ with $\mathrm{G}_{\mathrm{m}}=0.2$, $\mathrm{S}_{\mathrm{C}}=0.3, \quad \mathrm{G}_{\mathrm{r}}=0.2, \quad f_{\mathrm{w}}=10.0$ and $\mathrm{P}_{\mathrm{r}}=0.5$.

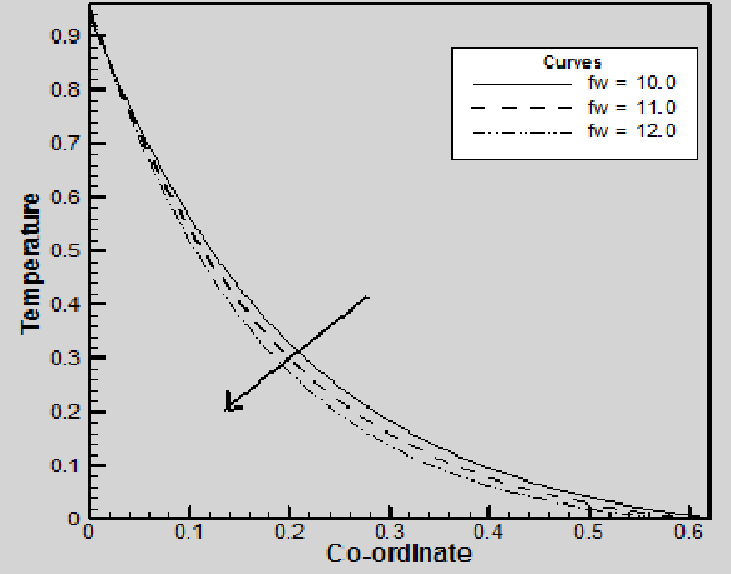

Fig. 6.7. Temperature profiles for different values of $f_{\mathrm{w}}$ with $\mathrm{G}_{\mathrm{m}}=0.2$, $\mathrm{S}_{\mathrm{C}}=0.3, \quad \mathrm{G}_{\mathrm{r}}=0.2, \quad \mathrm{E}_{\mathrm{C}}=0.1$ and $\mathrm{P}_{\mathrm{r}}=0.5$.

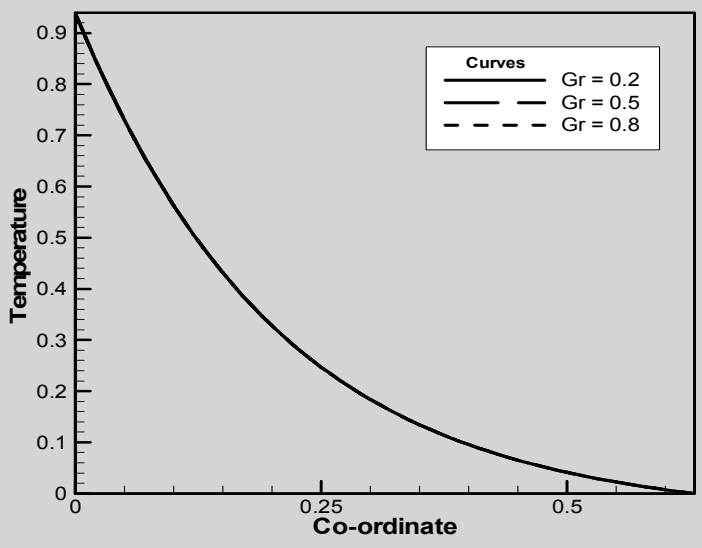

Fig. 6.8. Temperature profiles for different values of $\mathrm{G}_{\mathrm{r}}$ with $\mathrm{G}_{\mathrm{m}}=0.2$, $\mathrm{S}_{\mathrm{C}}=0.3, \quad \mathrm{E}_{\mathrm{C}}=0.1, \quad f_{\mathrm{w}}=10.0$ and $\mathrm{P}_{\mathrm{r}}=0.5$.

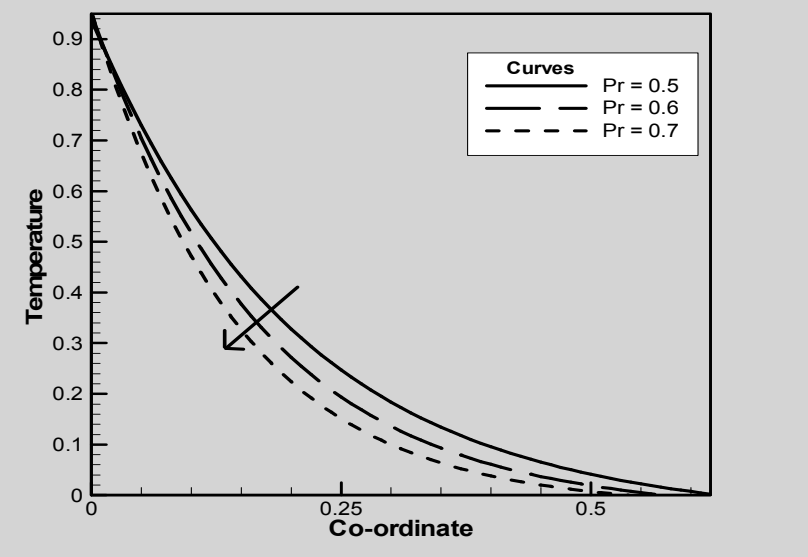

Fig. 6.9. Temperature profiles for different values of $\mathrm{P}_{\mathrm{r}}$ with $\mathrm{G}_{\mathrm{m}}=0.2$, $\mathrm{S}_{\mathrm{C}}=0.3, \quad \mathrm{G}_{\mathrm{r}}=0.2, \quad f_{\mathrm{w}}=10.0$ and $\mathrm{E}_{\mathrm{C}}=0.1$. 


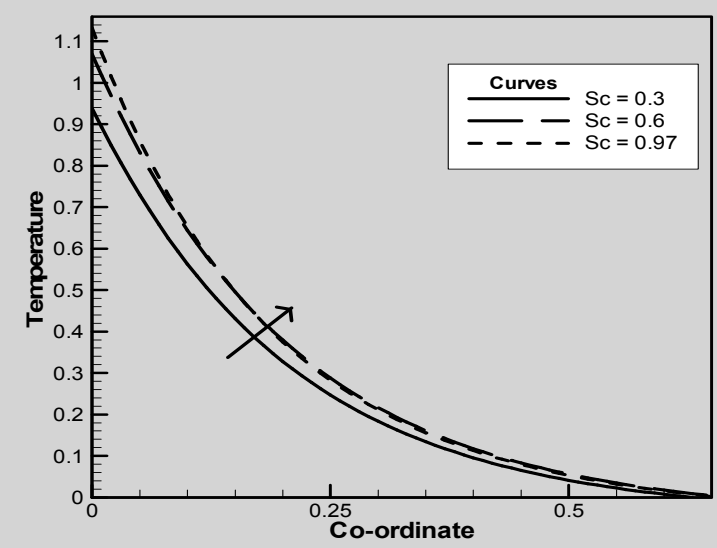

Fig. 6.10. Temperature profiles for different values of $S_{C}$ with $G_{m}=0.2$, $\mathrm{E}_{\mathrm{C}}=0.1, \quad \mathrm{G}_{\mathrm{r}}=0.2, \quad f_{\mathrm{w}}=10.0$ and $\mathrm{P}_{\mathrm{r}}=0.5$.

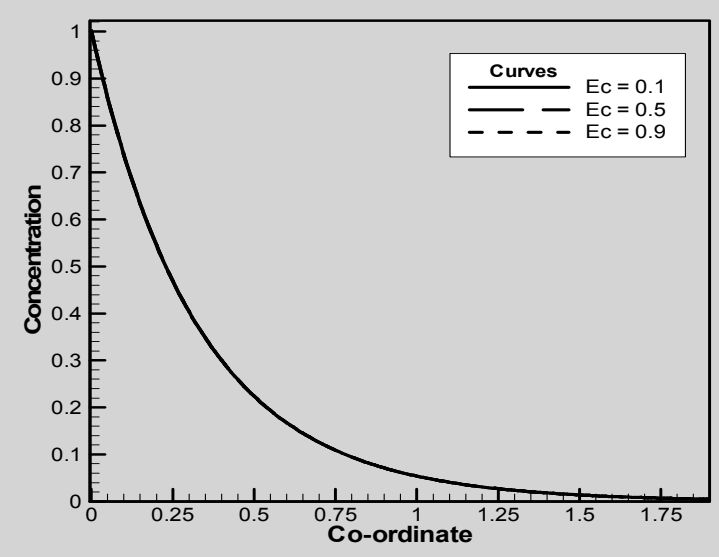

Fig. 6.11. Concentration profiles for different values of $\mathrm{E}_{C}$ with $\mathrm{G}_{\mathrm{m}}=0.2$, $\mathrm{S}_{\mathrm{C}}=0.3, \quad \mathrm{G}_{\mathrm{r}}=0.2, \quad f_{\mathrm{w}}=10.0$ and $\mathrm{P}_{\mathrm{r}}=0.5$.

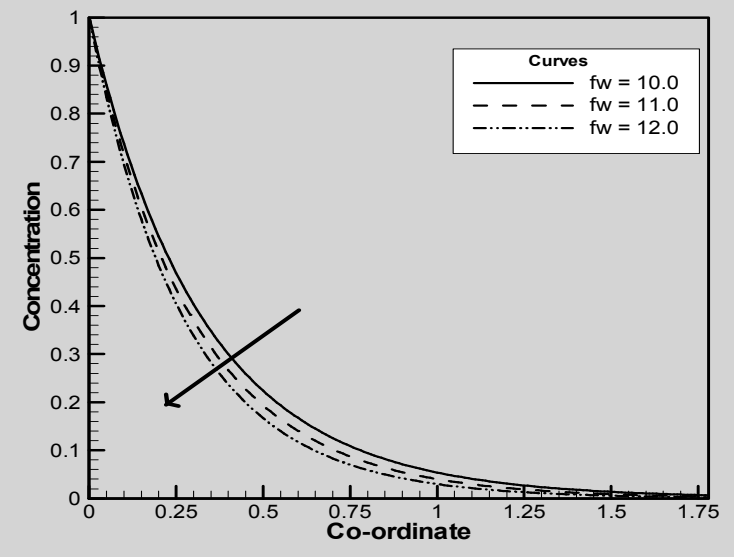

Fig. 6.12. Concentration profiles for different values of $f_{\mathrm{w}}$ with $\mathrm{G}_{\mathrm{m}}=0.2$, $\mathrm{S}_{\mathrm{C}}=0.3, \quad \mathrm{G}_{\mathrm{r}}=0.2, \quad \mathrm{E}_{\mathrm{C}}=0.1$ and $\mathrm{P}_{\mathrm{r}}=0.5$.

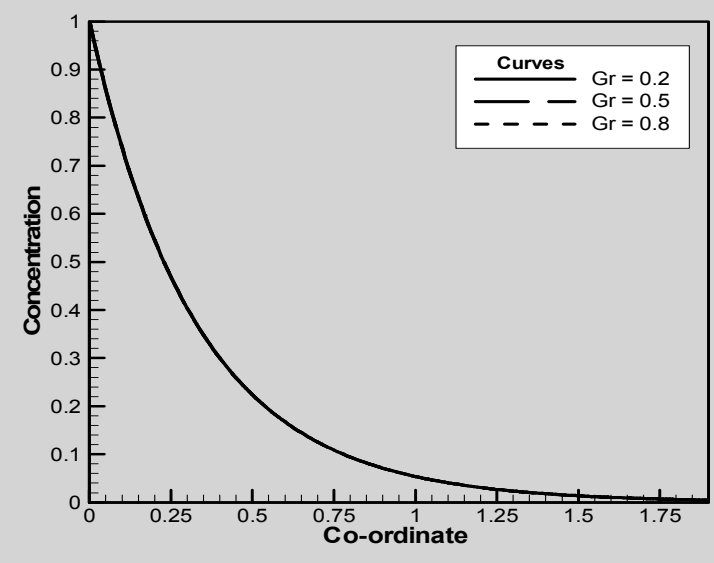

Fig. 6.13. Concentration profiles for different values of $\mathrm{G}_{\mathrm{r}}$ with $\mathrm{G}_{\mathrm{m}}=0.2$, $\mathrm{S}_{\mathrm{C}}=0.3, f_{\mathrm{w}}=10.0, \quad \mathrm{E}_{\mathrm{C}}=0.1$ and $\mathrm{P}_{\mathrm{r}}=0.5$.

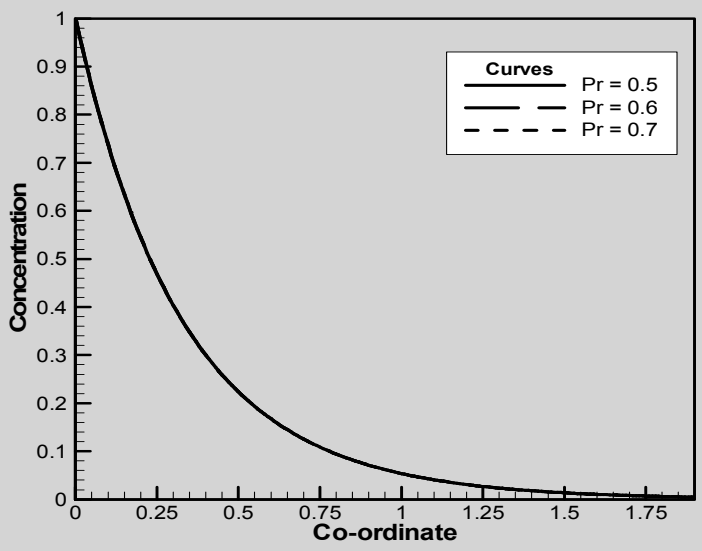

Fig. 6.14. Concentration profiles for different values of $P_{r}$ with $G_{m}=0.2$, $\mathrm{S}_{\mathrm{C}}=0.3, \quad \mathrm{G}_{\mathrm{r}}=0.2, \quad \mathrm{E}_{\mathrm{C}}=0.1$ and $f_{\mathrm{w}}=10.0$

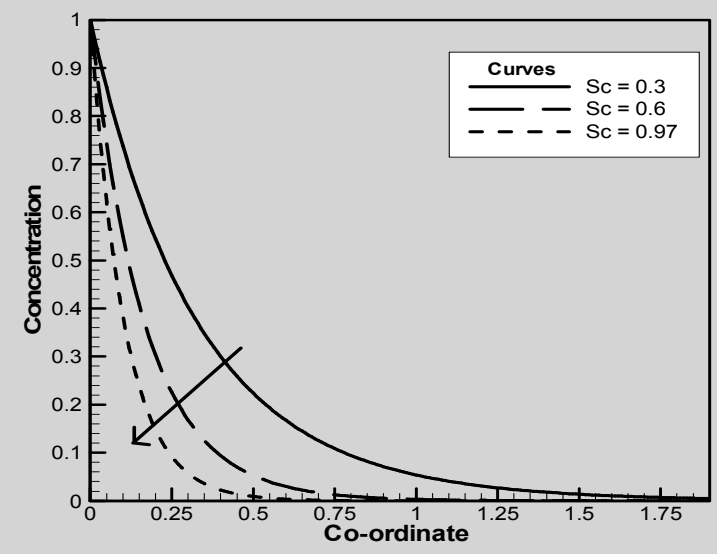

Fig. 6.15. Concentration profiles for different values of $\mathrm{S}_{C}$ with $\mathrm{G}_{\mathrm{m}}=0.2$, $f_{\mathrm{w}}=10.0 \quad \mathrm{G}_{\mathrm{r}}=0.2, \quad \mathrm{E}_{\mathrm{C}}=0.1$ and $\mathrm{P}_{\mathrm{r}}=0.5$. 


\section{Conclusions}

Viscous fluid behaviors of heat and mass transfer over a vertical plate with large suction have been observed in this work. The resulting governing dimensionless coupled non-linear partial differential equations have been solved analytically by perturbation technique. The results are shown for different values of important parameters as the Eckert number, suction parameter, Prandtl number, Grashof number and Schimdt number. Some of the important findings obtained from the graphical representation of the results are listed below:

1. The velocity profiles increases with the increase of suction parameter $f_{\mathrm{w}}$ while the velocity profile decreases with the increase of grashof number $G_{r}$.

2. The temperature profiles increases with the increase of suction parameter $f_{\mathrm{w}}$ while the temperature profiles decrease with the increase of Prandtl number $\mathrm{P}_{\mathrm{r}}$.

3. The concentration profiles decreases with the increase of Grashof Number $\left(G_{r}\right)$ and Schimdt number $\mathrm{S}_{\mathrm{C}}$.

\section{Acknowledgement}

The research project has supported Mathematics discipline, Khulna University. Therefore we have expressed gratefulness to Mathematics discipline, Khulna University for providing lab facilities.

\section{Nomenclature}

$\begin{array}{ll}S_{c} & \text { Schmidt number } \\ G_{r} & \text { Grashof number } \\ G_{m} & \text { Modified Grashof number } \\ C & \text { Concentration } \\ D_{c} & \text { Mass Diffusivity } \\ u & \text { Velocity component in the x-direction } \\ v & \text { Velocity component in the y-direction } \\ w & \text { Velocity component in the z-direction } \\ \nabla & \text { Differential operator } \\ P_{r} & \text { Prandtl number } \\ k & \text { Thermal Conductivity } \\ f_{w} & \text { Suction parameter }\end{array}$

$\begin{array}{ll}\beta & \text { Co-efficient of thermal expansion } \\ \beta^{*} & \text { Concentric expansion coefficient } \\ \delta & \text { Boundary layer thickness } \\ \mu & \text { Co-efficient of viscosity } \\ v & \text { Co-efficient of kinematic viscosity } \\ \rho & \text { Density of the fluid }\end{array}$

\section{References}

[1] M. Finston, (1956), Free convection past a vertical plate, $J$. Appl. Math. Phy., 7:527-529.

[2] E. M. Sparrow and J. L. Gregg, (1958), Similar solutions for free convection from a non isothermal vertical plate, ASME J. Heat Trans., 80:379-386.

[3] Soundalgekar and Ganesan P (1981), Finite-differential analysis of transient free convection with mass transfer on an isothermal vertical plate, International journal of engineering and science, 19:757-770.

[4] R. Camargo, E. Luna, C. Trevino, (1996), Numerical study of the natural convective cooling of a vertical plate, International journal of Heat and Mass Transfer, 19(1-2):89-95.

[5] G.D. Callahan, W.J. Marner, (1976), Transient Free Convection with Mass Transfer on an Isothermal Vertical Flat Plate, International Journal of Heat and Mass Transfer, 19(2):165-174.

[6] V.M. Soundalgekar, P.D. Wavre, (1977), Unsteady free convection flow past an infinite vertical plate with constant suction and mass transfer, International Journal of Heat Mass Transfer, 20(12):1363-1373.

[7] V.M. Soundalgekar, P. Ganesan, (1980), Transient free convective flow past a semi-infinite vertical plate with mass transfer, Journal of Energy Heat and Mass Transfer, 2(1):83.

[8] B. Gebhart and L. Pera, (1971), The nature of vertical natural convection flows resulting from the combined buoyancy effect of thermal and mass diffusion, International Journal of Heat and Mass Transfer, 14:2025-2050.

[9] Singh, A.K., A.K. Singh and N.P. Singh, (2003), Heat and mass transfer in MHD flow of a viscous fluid past a vertical plate under oscillatory suction velocity, Indian J. Pure Appl. Math, 34:429.

[10] Chamka and Khaled, (2001), Simultaneously heat and mass transfer in free convection, Industrial Engineering Chemical, 49:961-968. 